\title{
Maternal complications of hypertension in pregnancy - A five year study
}

\author{
Hemapriya ... ${ }^{1, *}$, Ambarish Bhandiwad ${ }^{2}$, Nagaraj Desai ${ }^{3}$ \\ ${ }^{\mathbf{1}}$ Assistant Professor, ${ }^{\mathbf{2}}$ Former Professor and HOD, ${ }^{\mathbf{3}}$ Adjunct Professor, ${ }^{\mathbf{1} 2}$ Dept. of Obstetrics and Gynecology, ${ }^{\mathbf{3}}$ Dept. of \\ Cardiology, JSS Medical College \& Hospital, JSS Academy of Higher Education \& Research, Mysore, Karnataka, India
}

*Corresponding Author:

Email: drpriya_911@ hotmail.com

Received: $11^{\text {th }}$ June, 2018

Accepted: $31^{\text {st }}$ July, 2018

\begin{abstract}
Introduction: Hypertension is the most common medical problem encountered in pregnancy. Approximately $18 \%$ of maternal deaths worldwide are due to hypertension complicating pregnancy. For every woman who dies, it is estimated that 20 others suffer severe morbidity or disability. The proportion of women surviving severe maternal complications has been proposed as a useful gauge for the evaluation of the quality of maternal health care and its determinants, with the potential to complement the information obtained from the reviews of maternal deaths.

Objectives: To study the prevalence and document the incidence of various maternal complications in women with hypertension in pregnancy.

Materials and Methods: A retrospective study was conducted at JSS hospital, Mysuru.

The medical records of women with hypertension in pregnancy from 2011 to 2015 were retrieved. The maternal complications were documented.

Results: The prevalence of hypertension in pregnancy was $8.5 \%$. Mild pre eclampsia was the most commonly encountered problem. Majority of the women developed hypertension only after 34 weeks. However, various complications such as abruptio placentae, HELLP, acute renal shutdown, disseminated intravascular coagulation, posterior reversible encephalopathy syndrome, retinal changes, and ascites were observed. The mortality rate was $1.6 \%$.

Conclusion: Hypertension continues to be a leading cause of maternal morbidity and mortality. However, with timely management, the complications and mortality can be reduced.
\end{abstract}

Keywords: Hypertension, Pregnancy, Pre eclampsia, Eclampsia, HELLP.

\section{Introduction}

Hypertension complicates 2-3\% of all pregnancies, and accounts for nearly $18 \%$ of maternal mortality globally. The national high blood pressure education program working group classifies hypertensive disorders in pregnancy as: Chronic hypertension, gestational hypertension, pre-eclampsia/eclampsia and preeclampsia superimposed on chronic hypertension. ${ }^{1}$ Preeclampsia is a disorder specific to pregnancy, affecting multiple organ systems. There is vasospasm of small vessels and formation of microthrombi leading to reduced organ perfusion. It complicates about 3-6\% of pregnancies, and in more commonly seen in primigravidas. ${ }^{2-4}$ Hypertension in pregnancy can have life threatening maternal and perinatal complications. ${ }^{5,6}$ Some of the common maternal complications are abruptio placentae, HELLP syndrome, eclampsia, acute tubular necrosis, disseminated intravascular coagulation and maternal mortality. The various perinatal complications are preterm delivery, IUGR, intra uterine and neonatal demise. ${ }^{7}$ Additionally, women with preeclampsia are at a higher risk of developing premature cardiovascular and cerebrovascular diseases and other chronic illnesses later in life. Although extensive research has been done, the cause of pre-eclampsia remains elusive. ${ }^{8}$

The objectives of our study were: To study the prevalence of different types of hypertensive disorders in pregnancy among patients referred to a tertiary care hospital.

To identify the incidence of various maternal complications in these patients.

To determine whether early detection and referral can decrease complications.

\section{Materials and Methods}

A retrospective study was conducted in the Department of Obstetrics \& Gynaecology at JSS hospital, Mysuru, which is a tertiary care teaching and referral centre. Patient records from January 2011 to December 2015 were retrieved from the medical records department. The demographic parameters such as the age, parity, residence and occupation were documented. The presence of multiple pregnancy, period of gestation at detection of hypertension, type of hypertension, the anti hypertensive drugs taken and use of magnesium sulphate were recorded. The various maternal complications studied were eclampsia, retinal changes ascites, renal failure, abruptio placentae, DIC, HELLP, PRES, ICU stay, ventilator support and maternal mortality.

\section{Statistical Analysis}

The collected data was analyzed using the SPSS software, version 21.0. 


\section{Results}

A total of 10,487 women delivered at JSS hospital from January 2011 to December 2015. 895 women were identified with hypertension in pregnancy, the cut off being 140/90 $\mathrm{mm} \mathrm{Hg}$; and their medical records were examined.

The prevalence of hypertensive disorders in pregnancy in our study was $8.53 \%$. The mean age of the women was 25.1 years. The majority $(45 \%)$ of our patients were in the age group of 21 to 25 years. A significant number $(15 \%)$ were less than 20 years of age. Only $1 \%$ of our study population was over 35 years of age. This shows that although hypertension is more common in the age groups of women less than 20 years, or more than 35 years, in developing countries, all age groups are at risk. $65.4 \%$ women came from the rural background, and $71.8 \%$ belonged to lower or lower middle class. $96 \%$ of women were home makers. $50.9 \%$ of our women were primigravidas. Only $7 \%$ of women had a pregnancy of fourth order or above. $3 \%$ of women had multiple pregnancies. $1 \%$ of the patients gave a history of preeclampsia in a previous pregnancy.

$66 \%$ of women had a late onset pre eclampsia; it was detected after 34 weeks of gestation. $10.6 \%$ of women had early onset pre eclampsia; ie at less than 32 weeks of gestation. The incidence of various hypertensive disorders according to the NHBP classification is shown in Fig. 1.

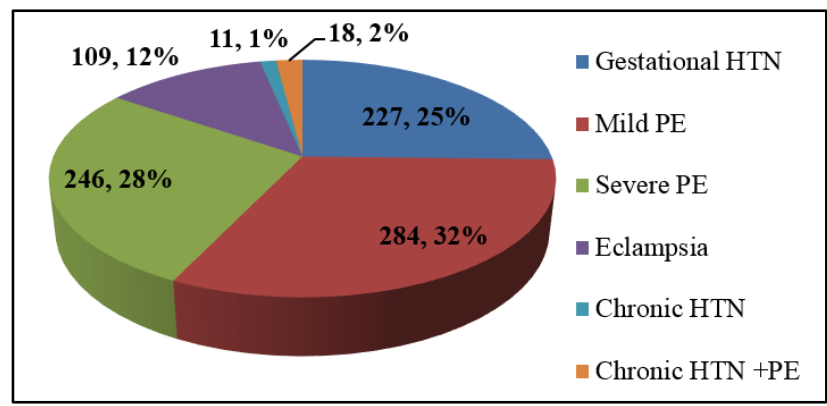

Fig. 1: Incidence of various hypertensive disorders in pregnancy

96\% of patients required one or more drugs for control of hypertension. Oral labetalol was the most commonly used, followed by nifedipine. In patients who required more than one drug, alpha methyl dopa was also used as the second or third drug, with good response. $34.6 \%$ of women required two or more drugs for the control of hypertension.

Fig. 2 depicts the use of magnesium sulphate for prevention and management of eclampsia. $\mathrm{MgSO}_{4}$ was used prophylactically in patients with diastolic blood pressure more than $110 \mathrm{mmHg}$, any imminent signs of eclampsia, complications like HELLP, abruptio, DIC, etc. Zuspan's regime was used in all patients, where $4 \mathrm{gm}$ iv loading dose was administered over 20 minutes, followed by $1 \mathrm{gm}$ per hour as an infusion, over 24 hours.

$83.6 \%$ of women did not develop any complication, and their peripartum course was uneventful. However, in the remaining $16.4 \%$, various complications were seen, eclampsia being the most common. The maternal mortality rate was $1.6 \%$, the most common cause of maternal death being eclampsia. Tables 1 and 2 depict the various complications encountered, and the different causes of maternal death.

The rate of caesarean section was quite high at $69 \%$, the most common indication being hypertension due to which a prolonged trial of labor was avoided. Obstetric indications such as malpresentation, fetal distress, cephalo pelvic disproportion, ante partum hemorrhage were the other common reasons for LSCS.
$42 \%$ women had a pre term delivery, of which $30 \%$ were late preterm, ie > 34 weeks of gestation. Only $16 \%$ of women had a full term normal vaginal delivery without any maternal or perinatal morbidity.

Hence, however mild the hypertensive disorder, the risk of blood pressure rising, and further maternal or perinatal complications developing always remains high.

Table 1: Maternal compllications of hyertensive disorders in pregnancy

\begin{tabular}{|l|c|c|}
\hline \multicolumn{1}{|c|}{ Complication } & Number & Percentage \\
\hline Eclampsia & 109 & 12 \\
\hline $\begin{array}{l}\text { Hypertensive } \\
\text { Retinopathy }\end{array}$ & 34 & 3.7 \\
\hline Retinal detachment & 8 & 0.9 \\
\hline Ascites & 57 & 6.4 \\
\hline Abruptio Placenta & 31 & 3.5 \\
\hline PRES & 24 & 2.7 \\
\hline HELLP & 11 & 1.2 \\
\hline ARF & 7 & 0.8 \\
\hline DIC & 6 & 0.7 \\
\hline Ascites, ARF & 5 & 0.6 \\
\hline HELLP, DIC & 3 & 0.3 \\
\hline HELLP, ARF & 3 & 0.3 \\
\hline Mortality & 15 & 1.6 \\
\hline
\end{tabular}




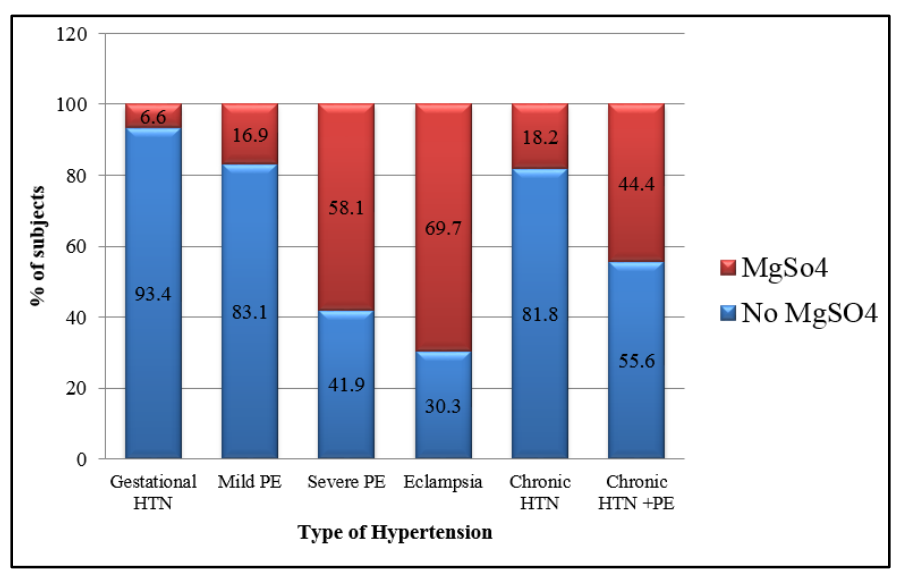

Fig. 2: Use of $\mathrm{MgSO}_{4}$

Table 2: Causes of maternal mortality

\begin{tabular}{|l|c|c|}
\hline \multicolumn{1}{|c|}{ Cause } & Number & Percentage \\
\hline Eclampsia & 7 & 46.6 \\
\hline Status Eclampticus & 2 & 13.3 \\
\hline DIC with MOF & 4 & 26.6 \\
\hline Uncontrolled PPH & 1 & 6.6 \\
\hline Pulmonary embolism & 1 & 6.6 \\
\hline
\end{tabular}

\section{Discussion}

Hypertensive disorders of pregnancy include chronic hypertension, gestational hypertension, preeclampsia and chronic hypertension with superimposed pre-eclampsia. Pre-clampsia complicates about $3 \%$ of pregnancies, and all hypertensive disorders affect about 5 to $10 \%$ of pregnancies. ${ }^{9}$ In our study, the incidence of HDP was $8.53 \%$. As more and more women are opting for pregnancy at a later age, and due to increase in the prevalence of maternal obesity, there is a significant increase in the number of women with chronic hypertension.

Primary prevention of pre-eclampsia is not possible as there is no effective screening method. Early identification of women who are at high risk of developing pre-eclampsia should be done. High risk factors such as age, body mass index, previous history of pre eclampsia, and family history of hypertension are identified. These women are advised frequent BP monitoring and USG surveillance to enable early detection and treatment of hypertension in pregnancy. ${ }^{10}$

Hypertension in pregnancy is associated with higher rates of maternal and perinatal mortality, and severe morbidity. Women with severe pre-eclampsia may develop various complications such as eclampsia, antepartum hemorrhage, HELLP syndrome, renal dysfunction, neurologic sequelae, and retinal detachment. ${ }^{9}$ Pre-eclampsia is a leading cause of both maternal and perinatal mortality in developing countries. ${ }^{12}$ In the developed world, with good health care facilities, the mortality and morbidity due to hypertensive disorders in pregnancy has significantly decreased. However, it still accounts for $13 \%$ of maternal mortality, despite early detection and timely intervention. ${ }^{11}$

Eclampsia, on the other hand, is a preventable condition. The use of prophylactic magnesium sulphate in women with severe pre eclampsia or in those with signs of imminent eclampsia has led to a decline in patients developing eclampsia. In our study, magnesium sulphate was used in prophylactically in $58 \%$ of women with severe pre eclampsia, and in $44 \%$ with super imposed pre eclampsia. The intravenous regime was used with $4 \mathrm{gm}$ loading dose followed by maintenance dose of $1 \mathrm{gm} / \mathrm{hr}$ for 24 hours.

The incidence of maternal complications in our study was $16.4 \%$, the most common being eclampsia, seen in $12 \%$ of women. Most of the women were referred with seizures or with signs of imminent eclampsia. Magnesium sulphate was the drug of choice to control seizures. Antihypertensive agents considered to be safe in pregnancy include methyldopa, labetalol, calcium channel blockers, and hydralazine. ${ }^{13}$ Oral or sublingual nifedipine, and labetalol given iv or orally are the drugs of choice to control blood pressure.

The maternal mortality rate in our study was $1.6 \%$, however, the morbidity, or near miss cases were much higher. This shows that a multidisciplinary care, at a tertiary care centre can decrease the mortality rate significantly. In a study by Abalos et al, it was seen that maternal near-miss cases were eight times more frequent in women with pre-eclampsia, and increased to up to 60 times more frequent in women with eclampsia, when compared with women without these conditions. ${ }^{11}$

Pregnancies complicated by hypertension may require early termination, resulting in iatrogenic prematurity, and a higher rate of caesarean section. ${ }^{12,13}$ Almost $20 \%$ of babies admitted to the neonatal intensive care unit are born to mothers with hypertension. ${ }^{14}$ In our study, the rate of caesarean section was as high as $69 \%$. The rate of pre term births was $42 \%$. Expectant management in women with early onset pre eclampsia, may allow prolongation of pregnancy with a better neonatal outcome. ${ }^{17}$ However, there is a significant risk of increased maternal complications and intra uterine fetal demise. Liu et al documented higher rates of early 
pre term delivery in women with severe pre eclampsia, who did not receive proper antenatal care. ${ }^{8}$

Maternal complications generally correlate with the severity of preeclampsia. ${ }^{15}$ They are related to the effect of severe preeclampsia on multiple organ systems, as well as due to intrapartum events. ${ }^{16}$ Apart from eclampsia, the most common complication seen in our study was Ascites, followed by hypertensive retinopathy and acute renal shutdown. Uteroplacental insuffiency can lead to various perinatal problems and intra uterine fetal demise, which is not discussed in the present study.

To conclude, we would like to stress that currently there are no well-established measures for preventing preeclampsia.6,19 To decrease preeclampsia-related mortality, appropriate prenatal care must be available to all women. Early detection, careful monitoring, and treatment of preeclampsia are crucial in preventing mortality related to this disorder. ${ }^{18,19}$

\section{References}

1. Report of the National High Blood Pressure Education Program. Working group report on high blood pressure in pregnancy. Am J Obstet Gynecol. 2000;183:S1-22.

2. Jenkins SM, Head BB, Hauth JC. Severe preeclampsia at 25 weeks of gestation: maternal and neonatal outcomes. Am J Obstet Gynecol. 2002;186:790-5.

3. Sibai BM, Mercer BM, Schiff E, et al. Aggressive versus expectant management of severe preeclampsia at 28 to 32 weeks' gestation: a randomized controlled trial. Am J Obstet Gynecol. 1994;171:818-22.

4. Sibai BM. Diagnosis and management of gestational hypertension and preeclampsia. Obstet Gynecol. 2003;102:181-92.

5. North RA, Brown MA. Gestational hypertension: how much should we worry? In: Belfort MA, Thornton S, Saade GR, eds. Hypertension in Pregnancy, $1^{\text {st }}$ edition. New York: Marcel Dekker, 2003:189-92.

6. ACOG Practice Bulletin No. 33. Diagnosis and management of preeclampsia and eclampsia. Obstet Gynecol. 2002;99:159-67.

7. Shear RM, Rinfret D, Leduc L. Should we offer expectant management in cases of severe preterm preeclampsia with fetal growth restriction? Am J Obstet Gynecol. 2005; 192:1119-25.

8. Ching-Ming Liu, Po-Jen Cheng, Shuenn-Dyh Chang, Maternal Complications and Perinatal Outcomes
Associated with Gestational Hypertension and Severe Preeclampsia in Taiwanese Women. J Formos Med Assoc. 2008;107; No 2:129-138.

9. Hutcheon JA, Lisonkova S, Joseph KS. Epidemiology of pre-eclampsia and the other hypertensive disorders of pregnancy. Best Pract Res Clin Obstet Gynaecol. 2011;25(4):391-403. doi: 10.1016/j.bpobgyn.2011.01.006. Epub 2011 Feb 18.

10. Hyde C, Thornton S. Does screening for pre-eclampsia make sense? BJOG. 2013;120(10):1168-70.

11. Abalos E, Cuesta C, Carroli G, Qureshi Z, Widmer M, Vogel JP, Souza JP;WHO Multicountry Survey on Maternal and Newborn Health. Preeclampsia, eclampsia and adverse maternal and perinatal outcomes: a secondary analysis of the World Health Organization. BJOG. 2014 Mar;121 Suppl 1:14-24. doi: 10.1111/1471-0528.12629.

12. Shmueli A, Meiri H, Gonen R. Economic assessment of screening for pre-eclampsia. Prenat Diagn. 2012;32(1):29-38.

13. Walker JJ. Pre-eclampsia. Lancet. 2000;356(9237):1260 5 .

14. National Advisory Body. Confidential enquiry into stillbirths and deaths in infancy report: 1998-1999. 8th Annual Maternal and Child Health Research Consortium.

15. Ngoc NT, Merialdi M, Abdel-Aleem H, Carroli G, Purwar M, Zavaleta N, et al. Causes of stillbirths and early neonatal deaths: data from 7993 pregnancies in six developing countries. Bull World Health Organ. 2006;84(9):699-705.

16. Brown CM, Garovic VD. Drug treatment of hypertension in pregnancy. Drugs. 2014;74(3):283-96.

17. Say L, Chou D, Gemmill A, Tuncalp O, Moller AB, Daniels J, et al. Global causes of maternal death: a WHO systematic anal- ysis. Lancet Glob Health. 2014;2(6):e323-33.

18. Mackay AP, Berg CJ, Atrash HK. Pregnancy-related mortality from preeclampsia and eclampsia. Obstet Gynecol. 2001;97:533-8.

19. Dekker G, Sibai B. Primary, secondary, and tertiary prevention of pre-eclampsia. Lancet. 2001;357:209-15.

How to cite this article: Hemapriya L,
Bhandiwad A, Desai N. Maternal complications
of hypertension in pregnancy- A five year study.
Ind J Obstet Gynecol Res. 2018;5(3):349-352.

